\title{
ARQUIVOS ABERTOS DE ROBERTO PIVA O PANORAMA DE UMA TESE
}

\author{
Ibriela Bianca Berlanda Sevilla \\ UFSC
}

RESUMO: Este texto apresenta um panorama de minha tese de doutorado defendida em outubro de 2015. A tese é resultado do estudo nos arquivos deixados pelo poeta paulistano Roberto Piva (19372010); um deles localizado na cidade de São Paulo em posse do herdeiro dos direitos autorais, 0 outro, guardado no Instituto Moreira Salles do Rio de Janeiro desde 2006. A investigação em ambos os arquivos trouxe a descoberta de dois livros inéditos: Corações de hot-dog e Out-door. 0 recorte que constitui o corpo desta investigação literária está formado pela análise de notas e poemas inéditos colhidos de ambos os arquivos e pela análise de poemas do livro Corações de hot-dog. 0 fio condutor para pensar a questão do arquivo e para guiar a abordagem de leitura do Corações de hotdog é a constante utilização da imagem do garoto, colocado em diferentes contextos, principalmente eróticos.

PALAVRAS-CHAVE: Roberto Piva. Arquivo. Poesia.

\section{OPEN ARCHIVES OF ROBERTO PIVA:}

\section{A THESIS OVERVIEW}

ABSTRACT: This text is an overview of my doctoral thesis defended on 0ctober 2015. The thesis is the result of studies on the archives left by Roberto Piva (1937-2010), a poet from São Paulo. One of the archives is kept in São Paulo with Piva's copyright owner, the other one is kept in the Moreira Salles Institute in Rio de Janeiro since 2006. The research lead to the discovery of two unpublished books entitled Corações de hot-dog and Out-door. The main line of investigation drawn throughout the analysis of Corações de hot-dog and several unpublished poems and notes found in Roberto Piva's archives consisted of the image of the boy, who is placed in different contexts, mainly erotic ones.

KEYWORDS: Roberto Piva. Archive. Poetry.

é Doutora em Literatura pelo Programa de Pós-Graduação em Literatura da UFSC. Pesquisadora do Núcleo de Estudos Literários \& Culturais. 


\title{
ARQUIVOS ABERTOS DE ROBERTO PIVA O PANORAMA DE UMA TESE ${ }^{1}$
}

\author{
Ibriela Bianca Berlanda Sevilla
}

Versar sobre um poeta deveria ser nada além de escrever sobre sua poesia. Mas como escrever desta poesia então sem entrar na esfera de seu criador? E por outro lado como falar de um "criador" se quem fala é a poesia mesma? Aos olhos dos homens, Deus é criador, mas quem fala são suas criaturas, elas é que têm a voz, a palavra e a habilidade incrível da comunicação. Esta foi uma das primeiras questões com as quais me deparei ao investigar os arquivos de Roberto Piva (1937-2010), poeta paulistano que teve sua produção poética publicada entre 1934 e 2008.

Uma poesia que "fala" de e em si mesma, se apresenta para o leitor em poemas feitos pela e através da vida, uma vida que em seu limite, encontra os limites da linguagem, encontra o sem limites da biblioteca. Mas poesia não comunica. Ela é uma criatura disforme, impossível de ser pega, pois é ouriço, na maioria das vezes não produz sentido, mas toca no corpo de quem a lê, bate e retumba no peito como um tambor. Nosso coração torna-se uma caixa acústica quando lemos os poemas deste irreverente, se me dou o direito de falar de vida; mas como não falar de vida se os arquivos (objetos de pesquisa deste trabalho) estão impregnados dela?

Piva, dizem, foi um homem corpulento que falava alto e gesticulava muito. Seu comportamento não era nada convencional, a começar (ou para terminar) por sua biblioteca. Se a biblioteca como a escritura pode ser espelho do artista, então sim, poderíamos dizer que Piva, o poeta, foi um homem mais do que excêntrico, consciente de seu papel na sociedade e muito preocupado com questões ambientais, que podem ser consideradas sua maior militância. Seus escritos estão também impregnados da preocupação com a necessidade da libertação sexual, que para ele objetivava uma mudança muito mais profunda e que iria além da aceitação da própria orientação sexual. Piva tomou para si e sua poesia o papel de incitar, mais do que tentar convencer do que quer que fosse. Incita com sua poesia o questionamento dos padrões

\footnotetext{
1 Texto proveniente da tese "Todos os pivetes tem o meu nome": imagens da subjetividade nos arquivos de Roberto Piva.
} 
estabelecidos para uma ética (social) e para uma estética (literária), que estavam, para ele, convencionalizadas no cenário brasileiro onde se insere.

Ao reflexo de sua densa biblioteca, a poesia de Piva incita o leitor a pensar a partir de uma perspectiva diversa, como seus antecessores mais radicais, Dante, Rimbaud, Baudelaire, Lautréamont, Artaud, Breton, entre tantos outros. Tomando de seus autores favoritos seus "toques de inferno" Piva engendra uma poesia que incita/excita a partir da confusão causada por suas imagens poéticas e da exaltação do que seria feio e criminoso, para desarrumar a imagem de um cenário "careta" de uma realidade onde já não há mais nada a ser profanado.

Cenários aliás que foram sendo modificados, revisitados e reengendrados no decorrer das publicações de Piva. Passaram das ruas e praças de São Paulo para as praias e arredores campestres do estado, transformando a crítica ácida e a agonia do corpo e da razão, presentes predominantemente nos primeiros três livros, em uma crítica satírica, inserida em uma cosmogonia própria atravessada por êxtases.

Ao mergulhar nos arquivos de Roberto Piva, um deles guardado por Gustavo Benini ${ }^{2}$ em São Paulo e o outro, pertencente ao acervo de poetas do Instituto Moreira Salles no Rio de Janeiro, tive a oportunidade de identificar essas movimentações e distintas nuances que toda sua obra, tanto a publicada quanto a inédita, apresenta quando reunida cronologicamente, incluindo o livro Corações de hot-dog, até então não publicado. Corações, foi realmente um achado muito importante para a obra do poeta. Este inédito, se tivesse sido publicado, fecharia a tríade notadamente erótica de Piva com os livros Coxas, publicado em 1979, e 20 poemas com brócoli em 1981.

$\mathrm{O}$ ineditismo de dois livros guardados nos arquivos de Piva, um deles ainda não lido ou analisado, intitulado Out-Door, bem como o ineditismo de inúmeros poemas belíssimos e potentes traz à tona a impossibilidade de fechar as publicações de Piva em uma obra completa. Pois o arquivo também é obra na medida em que é colocado à disposição de quem o queira acessar. Dentro de limitações e restrições, observando a lei dos direitos autorais, pesquisadores interessados podem ter acesso aos livros inéditos na instituição que os guarda, o IMS-Rio.

Ainda que a pesquisa literária preveja o acesso a arquivos quando possível,

\footnotetext{
${ }^{2}$ Gustavo Benini é o herdeiro do espólio de Piva.
} 
acessá-los de fato, foi colocar-se frente às complexidades intrínsecas desta categoria de documento, para além de seu bem ou seu mal, pensando com Derrida no "mal de arquivo". Foi também necessário lidar com as dificuldades de acesso em observação à lei de direitos autorais, dispêndio de recursos financeiros e tempo de pesquisa. Outro dos desafios com o qual me deparei, principalmente no arquivo privado (SP), foi encontrar a melhor maneira para catalogar e citar as partes do arquivo. Enquanto que o arquivo institucional (IMS-Rio) já apresenta uma organização em séries, tem uma maneira interna de atribuir referências para citações, um tipo semelhante de referenciação teve de ser feita para atender aos requisitos acadêmicos de uma tese.

Por outro lado, no arquivo guardado em São Paulo trabalhei no âmbito do ultra privado, tive toda a liberdade e tempo para vasculhar tudo que pude. Mantive sempre a cautela de ser o mais discreta e criteriosa possível ao fazer o recorte com o qual compus minhas análises, pois até certo ponto tudo importava, fosse um endereço ou um número de telefone, fosse a suspeita a letra manuscrita, que por muitas vezes precisei parar e comparar para poder decifrar o que estava escrito. É por esse motivo que falo não só de poesia, mas de vida, de uma vida literária cunhada à mão trêmula que persistiu na experiência literária até esgotar a vida, como diria Valéry.

O mergulho nos arquivos, por muitas vezes impossibilitou a subida à superfície para respirar. Sua densidade e variedade de formas arrastaram o olhar cada vez mais através de caminhos rizomáticos revelados um após o outro. É impossível ver tudo que um arquivo revela. Parece haver sempre um duplo escondido, algo ainda mais velado atrás de cada descoberta.

Desde de os escritos de infância, passando por documentos familiares, recortes de jornais e cópias de suas publicações guardadas entre livros, carimbos e fotografias, em estantes adornadas com estatuetas de suas divindades favoritas, chocalhos e tambores, foi possível ver o constante trabalho naquele material, pelo movimento de escrever, rasurar e escrever novamente em seus cadernos.

A descoberta de raridades como a primeira publicação de Piva, a Ode a Fernando Pessoa e o manuscrito do livro Piazzas fizeram mais enigmática ainda a incursão nos arquivos, pois nada pôde revelar porque aqueles dois itens não entraram na parte do arquivo que se tornou institucional, considerando o valor que teriam para aquela coleção. Tanto esta quanto várias outras perguntas ficaram sem respostas. Não há, por exemplo, qualquer indício ou 
parte do manuscrito do livro Paranoia (se é que existiu) nem indicação certeira do porquê o Corações de hot-dog não foi publicado, tendo sido guardado como um boneco, ordenado e revisado pronto para publicação no arquivo institucional do IMS-Rio. Quanto ao outro livro inédito intitulado Out-Door, vários dos poemas encontrados ali foram publicados em Ciclones (1997).

Em depoimento dado na noite da leitura de alguns dos poemas inéditos na Casa das Rosas em São Paulo, em 24 de setembro de 2013, Claudio Willer menciona que a recusa de publicação pela editora Brasiliense teria deixado Piva tão irritado, que o poeta teria recalcado o fato e guardado os inéditos entres seus papéis. Willer lembrou ainda que, na época, a editora estava lançando livros direcionados a um público mais jovem e convidou Piva para publicar, mas Corações de hot-dog foi recusado. Embora Willer atribua a recusa à temática homoerótica do livro, isso não pode ser confirmado.

Sergio Cohn, que de algum modo trouxe Piva de volta à cena literária dos anos 1990 através da revista Azougue, também tinha notícias da existência deste livro. Em uma conversa que tivemos em 30 de março de 2015, Cohn diz o seguinte:

No prefácio da segunda edição do Piazzas, em 1981, o Willer cita o Corações de hot-dog. Para mim, isso sempre marcou, porque virou um livro mitológico que eu precisava conseguir. Ele coloca como um livro que o Piva lançaria em seguida, então acho que podemos garantir que havia essa intenção. A Brasiliense estava editando diversos poetas da poesia marginal naquela época, Leminski, Ana Cristina Cesar, Chacal, Francisco Alvim, Waly Salomão. Faz sentido que o Piva tenha procurado o Caio Graco, que era editor na época, ou o Luiz Schwarcz. Mais provavelmente o Luiz Schwarcz, que criou essas coleções, e hoje é dono da Cia. das Letras. Sempre me soou estranho que o Piva tenha editado sua antologia pela L\&PM, e não pela Brasiliense. Foi o único.

Consultado sobre o assunto, Luiz Schwarcz responde que:

Todo o contato com o Roberto Piva era feito pelo Caio Graco. Eles eram amigos e de fato houve algum desentendimento relativo à publicação de um livro. Não acredito ter sido o homo erotismo a razão pois o Caio Graco era muito aberto e aceitava o tema com franqueza. Acho que dizer que havia planos de publicação que não se realizaram é verdade. Mas atribuir à temática a razão do desentendimento não me soa correto. Não sei dizer o que aconteceu. Eu não cheguei a ler o livro.

Ao que parece, Piva não compartilhava muito seus projetos nem seus 
escritos a não ser com editores quando efetivamente preparados para a publicação. Através da análise tanto das notas e poemas escritos nos cadernos e os datiloscritos dos dois livros inéditos, principalmente o do Corações de hotdog que traz marcas de revisão, é possível compreender que Piva foi um poeta muito rigoroso com seus escritos, sobretudo no que diz respeito à publicação de seus poemas. Antonio Zago, o amigo com quem Piva datilografou os poemas do Corações, depõe sobre a exigência e o rigor do poeta na hora de passar os poemas para sua versão que seria definitiva. Zago diz: "[...] às vezes a gente batia novamente, umas cinco, dez vezes, até ficar na postura que ele queria. Então a gente ia jogando.... 'não, faz de novo'... Que pra mim, tudo que eu aprendi sobre poesia foi fazendo esse trabalho." ${ }^{3}$

Assim como os poemas do Corações de hot-dog, tidos pelo poeta como "brinquedos loucos de uma dada-odisseia", seus cadernos também podem ser considerados brinquedos com os quais Piva inventou um personagem para si mesmo. Por vezes crítico, por vezes satírico e sempre revelando paixões, seus arquivos que mostram a composição de uma subjetividade artística, transbordam por todos os lados de subjetividades em devir. O que quero dizer com isso é que ficou evidente em minhas análises que o eu poético, lírico \& delirante, no caso de Piva, se manifesta de diferentes maneiras e formas, compondo distintos corpos e vozes que corroboram para formar um Eu enunciador sempre outro.

\section{O CORAÇÕES DE HOT-DOG "IN CONTEXT"}

Considerando que o livro Coxas foi reivindicado na revista Lampião da Esquina como um livro a entrar para a biblioteca gay, penso que o Corações, se tivesse vindo à público, também entraria para a coleção de sugestões aos leitores da revista; provavelmente por intermédio de Glauco Mattoso, poeta amigo de Piva que foi colaborador da revista. Contudo o Corações de hot-dog revela muito mais do que cenários gays e relações homoeróticas. Recuso-me a aceitá-lo como um livro gay. Ele é para mim, muito mais um livro erótico e em grande medida um livro sobre o êxtase atravessado de imagens satíricas e uma grande dose de irreverência. É no procedimento, na técnica poética que está, talvez, a maior beleza deste livro. As composições que vão de apropria-

\footnotetext{
${ }^{3}$ Entrevista com Antonio Zago feita em São Paulo em novembro de 2014.
} 
ções, reapropriações, montagens, anacronia e sincronia, simultaneidade de tempos e espaços, até a criação de cenários surreais, trazem para o presente do poema a urgência de pensar seu próprio tempo e realidade.

Antonio Zago, que escreveu o posfácio para o Corações de hot-dog observou que Piva opera uma integração e desintegração na poesia refletindo a fragmentação da cultura urbana. É também parte do procedimento poético de Piva, sempre no limite, nos bordes e nas tangências dos opostos. Seguidor de seu mestre dionisíaco, Piva parte do bem e do mal para o além onde alcança a poesia.

Em lampejos de simultaneidade temporal operada pelo poeta como um procedimento mnemônico de inclusão, transferência e transposição de realidades experimentadas, os poemas abrem-se em inúmeras e variadas dimensões. A primeira destas dimensões é o corpo, o garoto, que às vezes é o centro em torno do qual as outras imagens são compostas. Em alguns poemas as imagens que "ativam" a imaginação do poeta, por assim dizer, e que estariam consequentemente em uma primeira "dimensão" (imaginando o poema como um objeto multidimensional), são compostas pela evocação do nome de seus poetas favoritos: Dante e seu "Paraíso da Paixão" no poema "Corações de hot-dog", Virgílio e suas Bucólicas nos poemas "Verão" e "Bar Jeca", Lorenzo de' Medici e sua Canzona di Bacco no poema homônimo e no "Praça Marechal". Ao mesmo tempo em que estas referências literárias aparecem em primeiro plano nos poemas, temos referências a deidades de todos os tipos e a outros poetas que aparecem em segundo, terceiro ou quarto plano, figuras que nesta justaposição dão um efeito em que todo tempo é presente.

Desde fim do século XIX, início do século XX, Aby Warburg pesquisara intensamente os significados dos mitos e figurações da Antiguidade clássica para a sociedade do Renascimento. Para explicar a transmissão das imagens da Antiguidade para o presente ele cunhou a noção de Pathosformeln. Esta fórmula consiste no reconhecimento de imagens arquetípicas que retornam em contextos diferentes ao longo da história da arte. Warburg concebia a história das imagens através da estratificação de experiências diversificadas. Assim como as épocas se sobrepõem por meio dos diversos sedimentos geológicos, a história da arte vista de modo anacrônico, seria composta da "sobrevivência" das imagens estáticas que condensam a criação originária (pathos) com a repetição do cânone.

A partir de dados formais observados na representação do movimento 
das roupas e dos cabelos nas pinturas de Botticelli, Warburg buscou investigar as atitudes fundamentais que diferenciavam o homem da renascença daquele da Idade Média. Para ele a Antiguidade presente na sociedade florentina do final do século XV, não tinha nada da atitude apolínea clássica, mas ele percebeu ali um "pathos dionisíaco" que expressava estados emocionais "no limite da tensão". Carlo Ginzburg explica que:

Através da noção de Pathosformeln, as representações dos mitos legadas pela Antiguidade eram entendidas como "testemunhos de estados de espírito transformados em imagens", nas quais "as gerações posteriores... procuravam os traços permanentes das comoções mais profundas da existência humana."

Deste modo, Warburg observou que a sobrevivência das imagens da antiguidade clássica, ou seja, a "adoção das Pathosformeln" pelos artistas do Renascimento, mostrava além de traços fundamentais da natureza humana, uma completa ruptura com a arte e com o pensamento medievais.

A Antiguidade retomada na poesia de Piva, nas imagens de Dante, Virgílio e Lorenzo de' Medici e suas obras, e nas imagens de Dionísio, Priapo e os Sátiros é notadamente um recorte que reativa sentidos específicos, a partir de uma noção "ciclônica" de realidades experimentadas nas brechas imagéticas que ela engendra na poesia. Em um movimento ao revés daquele das pesquisas de Warburg, vamos aqui, conduzidos pelo procedimento delirante do poeta, da palavra para a imagem - imagens poéticas multidimensionais.

Mas o que mostram estas sobrevivências na poesia de Piva? Enquanto a Pathosformenln da antiguidade observada na arte do renascimento mostrou a ruptura com a Roma tradicional e a mudança de comportamento em direção ao helenismo, o que mostram os autores da renascença italiana que "sobrevivem" / aparecem na poesia de Piva imersos em uma atmosfera completamente erótica?

Para Walter Benjamin a língua realiza a conjunção entre os fragmentos erráticos e o princípio construtivo através do ritmo. Somente a musicalidade, escreve Didi-Huberman, "temas con contra-temas, medidas con desmesuras, tempi con polirritmos, timbres con texturas - permite introducir en el saber

${ }^{4}$ GINZBURG, Carlo. Mitos, emblemas, sinais: morfologia e história. Trad. Federico Carotti. São Paulo: Companhia das Letras, 1989, p. 44. 
del historiador el anacronismo de su objeto. ${ }^{15}$ De um modo muito semelhante podemos compreender, através da musicalidade e das alternâncias imagéticas, o anacronismo dos objetos poéticos manipulados por Piva. Os "brinquedos loucos de uma Dadá-Odisséia" em analogia ao "quebra-cabeça chinês", onde Benjamin viu "una primera prefiguración alegórica del principio cubista en el arte plástico" e que evocava, para ele, a "ação desintegrante da morte", ou da ebriedade, e principalmente "el trabajo construtivo del pensamiento."6

Este "princípio construtivo", que Benjamin entreviu na possibilidade de criar uma imagem única a partir de "elementos erráticos", emerge necessariamente do ato de pôr em jogo do próprio corpo em uma "montagem da experiência", cujo resultado final seria a "constituição de um saber". Um saber inserido no tempo, ou ainda, na possibilidade de ler o tempo nos brinquedos/poemas. Por outro lado, Agamben explica que o país dos brinquedos de Collodi é um lugar "em que os habitantes se dedicam a celebrar ritos e a manipular objetos e palavras sagradas, das quais, porém esqueceram o sentido e o escopo." Nesta observação, Agamben propõe pensar o tempo, ou ainda, o desmantelamento do tempo inserido na dimensão do jogo. Enquanto para Benjamin, brincar com imagens, em uma espécie de montagem de experiências, acaba por constituir um saber do tempo, Agamben entende que enquanto o homem joga manipulando seus brinquedos (pensaremos aqui em poemas), ele se insere no tempo sagrado, ainda que amparado pelo tempo humano.

Agamben nos lembra de que tudo que "pertence ao jogo pertenceu, outrora, à esfera do sagrado" e tudo que se presta ao jogo, tudo que é antigo, ainda que não tenha uma "origem sacra", pode se tornar brinquedo principalmente em mãos infantis. Ele esclarece que:

O caráter essencial do brinquedo - o único, se refletirmos bem, que o pode distinguir dos outros objetos - é algo de singular, que pode ser captado apenas na dimensão temporal de um "uma vez" e de um "agora não mais" (com a condição, porém, como mostra o exemplo da miniatura, de compreender este "uma vez" e este "agora não mais" não apenas em um sentido diacrônico, mas

5 DIDI-HUBERMAN, Georges. Ante el tiempo. Trad. Oscar Antonio Oviedo Funes. Buenos Aires: Adriana Hidalgo, 2008, p. 212.

${ }^{6}$ Cf. Ibidem, p. 211.

7 AGAMBEN, Giorgio. Infância e História. Trad. Henrique Burigo. Belo Horizonte: Editora UFMG, 2005, p. 85. 
também em sentido sincrônico). ${ }^{8}$

E mais adiante, completa:

O brinquedo é uma materialização da historicidade contida nos objetos, que Lee consegue extrair por meio de uma manipulação particular. Enquanto, na verdade, o valor e o significado do objeto antigo ou do documento é função da sua antiguidade, ou seja, do seu presentificar e tornar tangível um passado mais ou menos remoto, o brinquedo, desmembrando e distorcendo o passado ou miniaturizando o presente - jogando, pois tanto com a diacronia quanto com a sincronia - presentifica e torna tangível a temporalidade humana em si, o puro resíduo diferencial entre o "uma vez" e o "agora não mais". 9

Assim, pensando o poema em analogia com este brinquedo que contém em si tanto a diacronia quanto a sincronia do tempo, pois que manipula imagens do passado no presente, transformando-as em significantes modificados, justapostos em diversas dimensões, montados de fragmentos, os poemas parecem trazer o tempo do "era uma vez" para o "é agora". Se o jogo rompe a ligação entre passado e presente fragmentando a estrutura temporal em eventos e transformando a sincronia em diacronia, os poemas enquanto "brinquedos loucos de uma Dadá-Odisséia" (aqui também há justaposição de tempos da história da arte) transformam, pela anacronia, o tempo em um infinito presente.

Os "brinquedos loucos" de Piva tiram de cena a subordinação ao trabalho para focar no jogo, que entra no contexto como seu contrário, suspendendo o tempo diacrônico, o medo da morte (pois jogar é pôr-se em jogo) e a seriedade da vida ${ }^{10}$, pois justamente a poesia "está para além da seriedade, naquele plano mais primitivo e originário a que pertencem a criança, o animal, o selvagem e o visionário, na região do sonho, do encantamento, do êxtase, do riso", afirma Johan Huizinga. ${ }^{11}$

Reproduzo a seguir alguns dos poemas do livro inédito Corações de hotdog, citados acima. Dada a limitação do espaço as análises foram excluídas deste texto.

\footnotetext{
8 Ibidem, p. 86.

9 Ibidem, p. 87.

${ }^{10}$ Cf. BATAILLE, Georges. Estamos aquí para jugar o para ser serios? In: La felicidad, el erotismo y la literatura. Trad. Silvio Mattoni. Buenos Aires: Adriana Hidalgo, 2008, p. 207.

11 HUIZINGA, Johan. Homo Ludens. Trad. João Paulo Monteiro. São Paulo: Perspectiva, 2000, p. 88.
} 


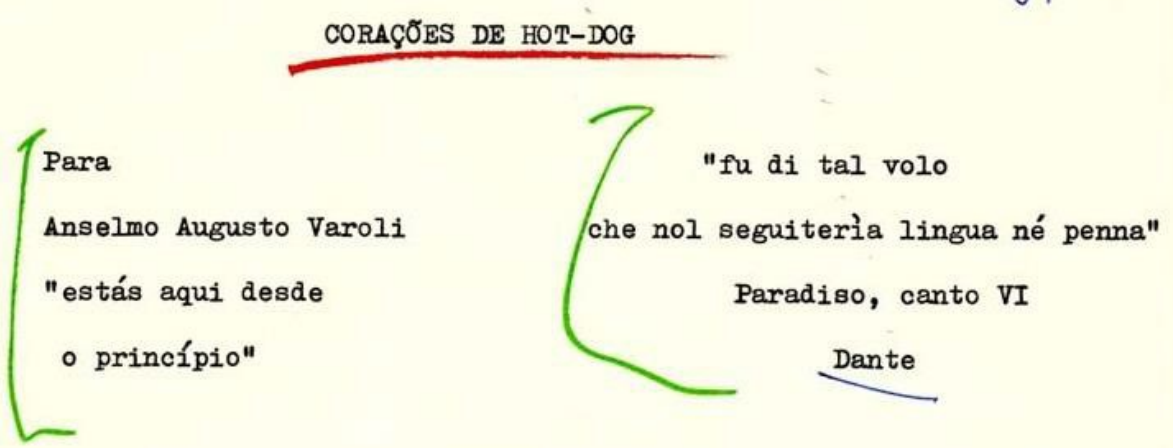

ônibus

viagem de Dante no Paraíso da Paixão<smiles>[C]1C[Te]1</smiles>$$
3 \text { AMOR = LUZ }
$$

Guararema Mogi São Paulo

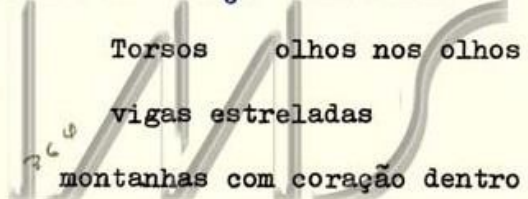

38

mártir é o rabo da mula

304

fogo no rosto do meu amor

$3^{2} 6$

Sol entre nuvens cabeludas

pés inchados

potência da potência

olhos de novo

Osiris crucificado em

seus olhos?

brejos

346

vento janela cortinas explodindo

boca sem sumo

$33^{25}$

órgão em sintonia 


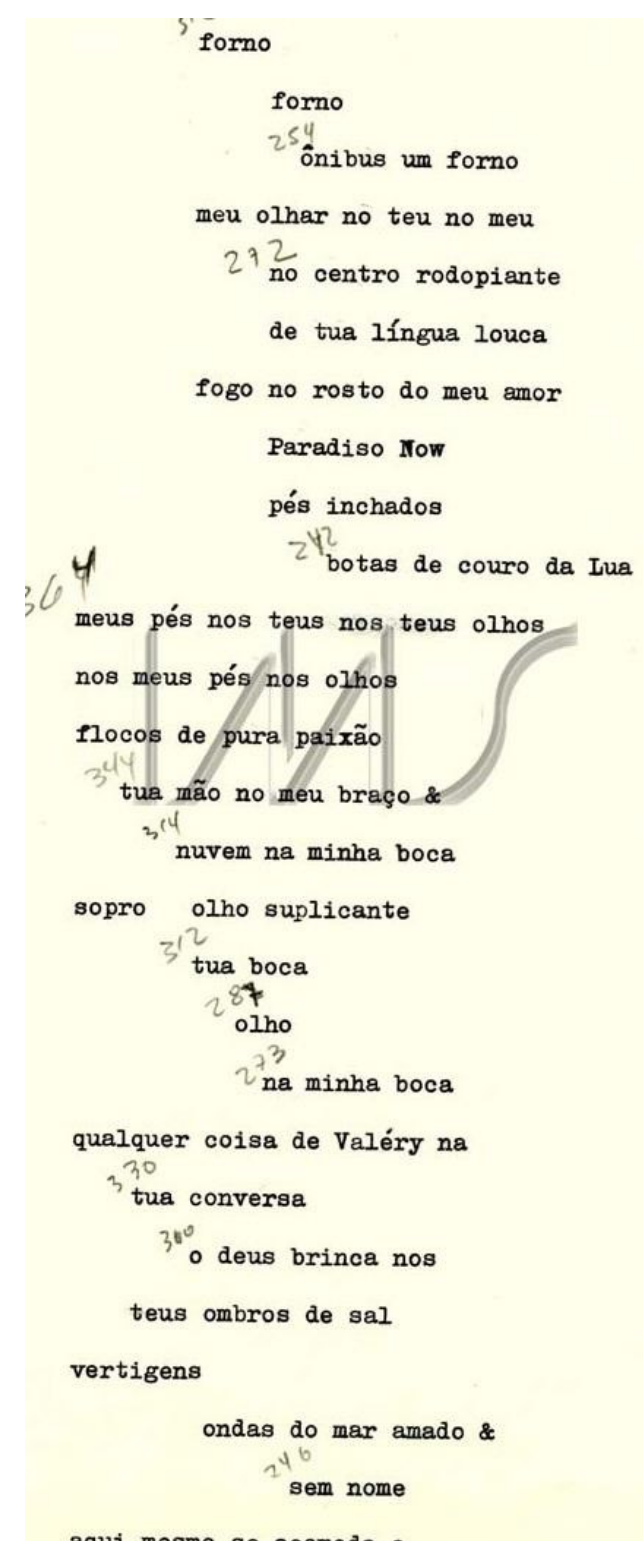

aqui mesmo se acomoda o

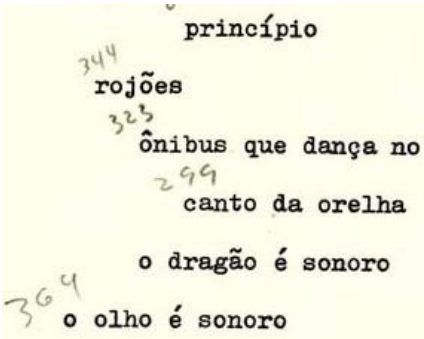

eu posso dançar na tua boea de 2द4 305

trevas rosadas

quaresmeiras trópico no suor da mão $2+9$

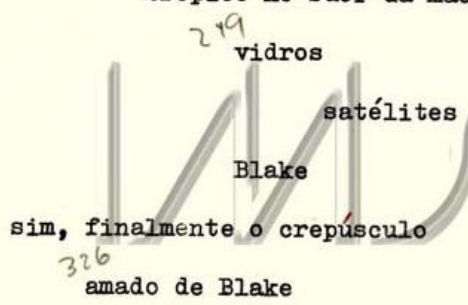

flor espirithal no canal cósmico

só você

só você

desenhar um pássaro de água no seu rosto 240 príncipe

Rei do Universo

pele sem nada dentro

você ficou na minha pele

EU QUERO VOCE AGORA

333

vento

ondas de formigas marinhas 

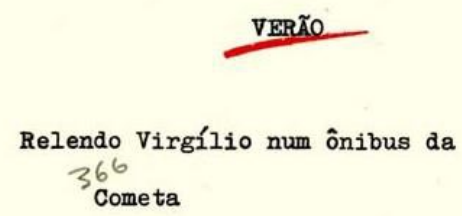

mumo aos litorais bucólicos com

discos-voadores experimentados

faço o mundo sangrar no pára-brisa

Corydon enfeitando o coração

antes de ler Notícias Populares

acariciado nas coxas por

algum Alex distraído

Festejo Iemanjá na Sibila de Cumae

batendo cabeça no altar de Mecenas

ressuscitado

que vai pagar arinks

pro poeta
BAR JECA

qualquer coisa de Virgílio na alma daquele

$$
\text { garoto }
$$

- formose puer, nimium ne crede colori

mascando minha macauva incrementada

sonhos sonhados de sanhaços

chiclé de bola de uma religião

qualquer

ruas como rédeas nas minhas luvas

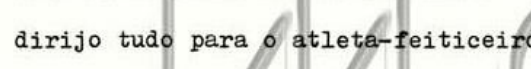

deus-porco com tetas de fora

além do trem \& do varal

- formose puer, nimium ne crede colori

qualquer coisa de Virgílio na alma daquele garoto
Lorenzo:

$$
\text { chama }{ }^{u^{3}} \text { pajem adolescente }
$$

que velava teu sono banhado em ácido vem no doce calombo da av. São João desfilar o coração nu \& atrapalhado os garotos estão mais sábios agora os clássicol têm maior circulação \& não perturbam o Sono ecos estranhos provocam tua $3 \longdiv { 2 }$

$$
27^{3}
$$

chupando sorvete de nozes

\& relembrando poemas

de Lorenzo de' Medici

garoto vadio dobrando o sonho

pombas revoam sobre as caras

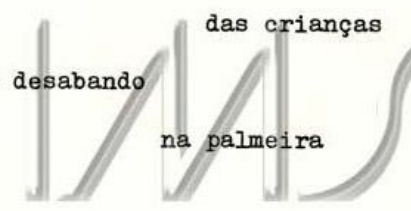

tua poesia chapada é uma

teia de aranha de estrelas

como o centurião Vico \& seu Bestione

da Destruição

quem quiser ser alegre seja:

do amanhã não há certeza 
Embora os poemas apresentados tenham evidentemente suas particularidades de composição e de abordagem temática, o Corações de hotdog como um todo apresenta, principalmente, uma experiência estética baseada na paixão extática que se dá no corpo, através do corpo e está voltada para ele. Essas relações extáticas parecem extrapolar a ideia da imperfeição e incompletude do homem frente ao seu deus. Não se trata da busca de uma verdade, nem de uma elevação mística, ou salvação, na medida em que os poemas apresentam não um homem afastado de deus, mas que se encontra ao lado dele, não ao lado do Deus católico, mas entre os deuses pagãos que ora são os da mitologia, ora são as entidades da umbanda ou do candomblé e, em outros tantos momentos, os deuses aparecem na figura de poetas, os seus favoritos, geralmente canônicos.

Assim, a subjetividade que se entranha na poesia de Piva, os eus e os objetos a ela relacionados convivem ora em harmonia, ora em tumulto com deuses transfigurados e personagens de épocas diferentes transpostos para o contexto do poema. Não é possível, desta maneira, determinar, delinear ou conceber esta subjetividade que insiste em manter seu lugar nos poemas, a não ser como um sujeito delirante, "pluriforme", pansexual, extático.

O êxtase figurado no Corações de hot-dog é muitas vezes sinônimo de espasmo sexual, leva para fora do corpo, que é um delírio, mas volta ao corpo, como o movimento do bumerangue - a exemplo dos últimos versos do poema "Corações de hot-dog". Esta poesia nos mostra que no momento do êxtase, em que uma individualidade se funde com a do outro presente no ato erótico, a supressão do limite de si mesmo e do outro é a violência mais profunda em direção à subjetividade. Dado que a relação erótica pressupõe a dissolução dos limites do eu e sua fusão com o outro ou com um fora, então o eu poético, como um sujeito fora de si, não é senão sua própria dissolução, ou seja, uma completa sublimação do eu.

Nietzsche encontrou na arte a única alternativa possível para libertar o homem do que ele chama a "moral de rebanho", fundada nos princípios de valor do cristianismo. A arte opera no campo da ficção "na qual precisamente a mentira se santifica" e a "vontade de ilusão [...] opõe-se bem mais radicalmente do que a ciência ao ideal ascético." ${ }^{12}$ Assim, pensando com Nietzsche, a poesia erótica de Piva, por mobilizar impulsos como a paixão, o desejo e o êx-

12 NIETZSCHE, Friedrich. Genealogia da moral: uma polêmica. Trad. Paulo César de Souza. São Paulo: Companhia das letras, 2009, p. 132. 
tase, participa, ela também, de uma oposição a qualquer ideal ascético, seja comportamental, pelo afastamento do corpo de experiências extremas como o delírio; seja literária, por uma escrita desprovida de corpo, em que a palavra está vazia de qualquer princípio subversivo. Devemos lembrar, contudo, que diferentemente de Bataille, Nietzsche não estava interessado em explorar a ligação do sagrado com o homem através do corpo, coisa que aparece muito nos arquivos e em grande parte dos poemas de Piva. Nietzsche levou o corpo para sua filosofia para pensar o instinto animal que foi por muito tempo obliterado em favor de uma vida em comunidade delimitada pelas instituições, questão esta que também foi tratada, com certa insistência e até necessidade, na obra de Piva.

O êxtase em Corações de hot-dog não deixa de ser uma conexão com a esfera sagrada e tampouco deixa de ser uma volta à condição instintiva do homem que não pode ser aprisionado; se dá através do corpo e vai ao encontro das divindades pagãs e entidades espirituais das religiões afro-brasileiras que são tão divinas e sagradas quanto os garotos em seus múltiplos epítetos, e os animais em seus habitats mais selvagens, gerando um amálgama de sensações contraditórias.

Ao utilizar-se do erotismo ao invés da pornografia, este inédito entra no âmbito de um pensamento segundo o qual somente o sexo em seu extremo, talvez até como meio de vida, no caso dos michês (figura presente em vários poemas), poderia fazer sentido em uma realidade castradora. Através de uma linguagem delirante, irônica, satírica, Piva mostra, em suas imagens, a primazia do desejo como ponto fundamental da experiência poética que desemboca em uma política do corpo erotizado.

Talvez com o Corações de hot-dog, Piva tivesse entrado de vez no círculo da poesia "gay" brasileira, e por isso mesmo não o tenha publicado. Quando em 1980, no prefácio da segunda edição do Piazzas, Claudio Willer menciona dois livros ainda inéditos de Piva, o Vinte poemas com brócoli ("Vinte", no lugar de "20", como ficou o título quando foi publicado), e o Corações de hotdog, claramente desconsiderando a não publicação dos dois livros. A questão é que houve uma escolha; não se pode dizer com certeza se esta escolha foi do próprio autor, ou se de alguma editora ao recusá-lo, o fato é que o livro levado a público foi somente o 20 poemas com brócoli (publicado por Massao Ohno em 1981), enquanto o Corações de hot-dog permanece inédito até hoje.

Levando em conta a emergência do gênero "Gay" como bandeira política 
em prol da inclusão social e, mais ainda, o estabelecimento de um nicho de mercado direcionado ao público gay, que abrange o turismo, moda e produtos culturais, nos anos 1980, é bem provável que Piva tenha se recusado a lançar este livro depois do 20 Poemas com Brócoli. O 20 poemas, considerado pelo próprio autor como seu livro mais "trabalhado", em termos de técnica, expressa uma resposta de Piva, ainda que contida, ao tradicionalismo das letras naquela época, o que ele chamou ironicamente de "riminha safada de véu \& grinalda".

Piva foi incluído, ao lado de Glauco Mattoso, como um autor homoerótico, por Gilmar de Carvalho em seu ensaio intitulado "Alteridade e Paixão", publicado na revista CULT (o autor faz referência à Antologia Poética de 1985, que pouco mostra de homoerotismo). Contudo, nem o que pudemos ler em seus arquivos, nem sua obra publicada, que foi lida mais enfaticamente sob o prisma de questões da cidade de São Paulo, à luz de uma comunidade periférica e anárquica, poderiam ser incluídos, como um todo, na tradição da literatura gay; homoerótica talvez, mas não gay.

Quanto ao Corações de hot-dog, o que vemos em suas composições hiperbólicas é a busca do poeta pelo exato inverso de uma vivência normalizada da homossexualidade: o maior valor de sua obra segue sendo a transgressão. E o erotismo funciona, tanto nos arquivos inéditos quanto na poesia publicada, como um meio de explicitar o corpo, não somente pela resistência a um domínio moral e militarizado, mas também e principalmente, como proposição de um modo de ser num universo poético em que algo agônico e dionisíaco é sempre atravessado e acompanhado de um suspiro extático.

Em sua autobiografia digitada e encadernada, designada como "Caderno de Memórias", entre seus arquivos no IMS-Rio, podemos ler uma crítica sobre o que Piva pensava da cultura gay:

Nos anos oitenta, a invenção do modelo "gay" caracterizou o estilo americano da homossexualidade, esse modelo degradou a cultura ritualística. As características da iniciação se perderam e transformaram-se em algo amorfo, numa cultura de massa. A liberdade sexual concedida pelo poder e os modelos apresentados pela televisão causaram um desastre maior do que todos os anos de ditadura militar vividos pelo país.

$[\ldots]$

Nos anos sessenta as pessoas misturavam-se. Nos bares não se sabia quem era o que porque todo mundo transava com todo mundo. Esse modelo norte-ameri- 
cano acabou com a grande ternura e aquela devassidão espontânea do garoto brasileiro, estabelecendo esse modelo "gay/gay" que é algo universotário.

[...]

O modelo "gay" norte-americano serve ao consumo de massa, para poder fazer "lobby" de sauna, refrigerante, marca de carro, jeans e tudo que possa ser consumido. Eu acredito que essa divisão é fomentada pela imprensa, fomentada pelos donos de boates voltadas à clientela "gay". O Brasil é muito poligâmico, muito bissexual. Essas divisões são muito esquisitas, muito rígidas. Elas não cabem para o país do carnaval, onde homem casado se veste de mulher. ${ }^{13}$

Piva demonstra uma melancolia ao comparar o modo "escondido" das aventuras homossexuais nos idos dos anos 1960 com a "liberdade sexual concedida pelo poder", nos anos 1980 . Talvez por isso, o poeta tenha optado por composições satíricas em torno do homossexual afeminado - "Cheio de mumunhas/vinha desmunhecando o garoto/matusquela", por exemplo ${ }^{14}$ poema com o qual Piva expressa sua opinião sobre o "modelo americano" a que se refere no texto. Ainda, na mesma autobiografia, Piva critica a revista Lampião da esquina, primeiro por nunca ter sido convidado a publicar um poema - "nunca me convidaram para escrever um poema" - e por endossarem, de certa forma, o modelo "bofe/bicha" que, para Piva, não significava homossexualismo de fato, mas um modelo imposto de adoração a um feminino estilizado.

Embora, de fato, não tenha publicado poema algum na revista, a Lampião da esquina foi um meio de divulgação da poesia de Piva entre homossexuais. A primeira aparição do nome de Piva como um poeta "homossexual-proletário [...] autor de diversos livros", foi na décima edição, de março de 1979, na

13 PIVA, Roberto. Caderno de Memórias: Incipit: "Meu nome é Roberto [...]”, Excipit: “[...] marche sobre um abismo". Arquivo Roberto Piva: IMS-RJ, s/d. (Data provável 1994).

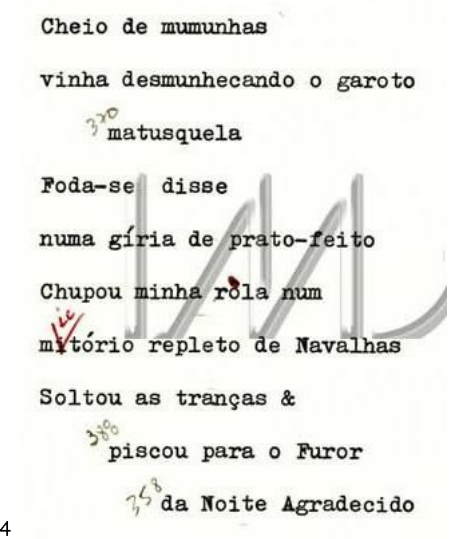

PIVA, Roberto. Corações de hot-dog. Arquivo Roberto Piva: IMS-Rio, inédito, p. 19. 
matéria que noticiava um debate sobre as "minorias" organizado por estudantes da USP. Piva compôs a mesa de discussão junto de João Silvério Trevisan e Darcy Penteado, editores do jornal, e mais três integrantes do grupo Somos, além de autoridades da universidade. ${ }^{15}$

$\mathrm{Na} 14^{\mathrm{a}}$ edição, a revista publica uma espécie de "teaser", já noticiando que o livro Coxas estava disponível sob reembolso postal e os exemplares poderiam ser reservados. Da $15^{\mathrm{a}}$ até a $18^{\mathrm{a}}$ edição, Coxas reaparece como sugestão de leitura. Na edição de setembro de 1979, o anúncio do livro é seguido por uma breve crítica assinada por Glauco Mattoso intitulada "O poeta das coxas". Mattoso chama Piva de "poeta cosmopaulistano" (tratamento completamente diferente do primeiro em que fora chamado de "poeta-proletário"), e localiza o Coxas no contexto da contracultura, a partir das epígrafes dos poemas e pelo livro ter sido lançado simultaneamente aos LPs dos Beatles e de Bob Dylan. Comenta a "ficção poética" do livro, o nome simbólico de seus personagens ("Lindo Olhar", "Coxas Ardentes", "Lábios de Cereja", o garoto mecânico "Rabo louco", a garota "Onça humana", alguns dos integrantes do clube "Osso \& liberdade") e os lugares pouco frequentados (de São Paulo) pela literatura - a zona leste, ele ressalta. Mattoso reafirma o lugar de poeta maldito de Piva: "Piva tem de fato todos os ingredientes dos chamados poetas malditos do século passado, do nosso e (por que não?) do próximo. E toda a bagagem dos ismos malcomportados, do dada ao existencial." ${ }^{\text {"16 }}$

Nos anúncios do livro, que se repetem, a revista utiliza o termo "Nossa poesia" - "Nossa poesia está nas ruas. 'Coxas' é o melhor exemplo da nossa poesia." - aqui, antes de ser "nossa poesia" brasileira, devemos ler como "nossa poesia" guei, propriamente grifado como na revista. Embora não haja, no comentário de Mattoso, qualquer menção ao termo gay, tendo preferido aproximar a poesia de Piva à tradição das vanguardas e aos poetas malditos, a revista Lampião da esquina, querendo ou não, elege o Coxas como o livro de poemas "guei", e, consequentemente, Piva como um de seus melhores representantes.

Nas edições 27 e 28, 31 e 32, entre 1980 e 1981, é a segunda edição do Piazzas que entra para as sugestões de leitura da revista na seção "Livros no-

\footnotetext{
${ }^{15}$ DANTAS, Eduardo. Negros, mulheres, homossexuais e índios nos debates da USP: Felicidade também deve ser ampla e irrestrita. Lampião da esquina, Rio de Janeiro, ano I, n. 10, março de 1979, p. 9.

${ }^{16}$ MATTOSO, Glauco. O poeta das coxas. Lampião da esquina, Rio de Janeiro, ano I, n. 16, setembro de 1979, p. 17.
} 
vos na Biblioteca Universal Guei". Também nestes anúncios a posição de maldito-marginal observada por Mattoso é repetida. O poeta é colocado ao lado de Baudelaire, Ginsberg, Sade e Genet e o apelo sexual do livro é enfatizado, pois apresentado como uma "introdução à orgia", atribuição de Claudio Willer. O Piazzas, diferentemente do Coxas, está colocado entre os livros da "Biblioteca Universal Guei" e não como um livro que traduz a "nossa poesia". De todo modo a revista Lampião elegeu, em seus três anos de existência, estes dois livros de Piva como literatura guei.

Italo Moriconi diferencia o que poderia ser considerada literatura gay da homoerótica:

Literatura homoerótica é um termo mais geral, algo que pode ser encontrado em todas as épocas [desde a literatura Greco-romana a Whitman, por exemplo], ao passo que 'literatura gay' propriamente dita seria uma vertente mais contemporânea, vinculada ao processo histórico de liberação gay, de conscientização gay, seja lá como se queira chamar esse processo; em suma, seria literatura homoerótica pós-68, pós-Stonewall. ${ }^{17}$

É preciso considerar a atualidade do livro inédito de Piva, composto de poemas escritos entre 1974 e 1981, justamente o momento em que o movimento homossexual na sociedade brasileira se fazia ver como afrontamento e enfrentamento político e até religioso. Movimentação que ressurge hoje com mais força, e envolta em polêmicas lançadas pelo movimento conservador religioso também emergente no país. Na década de 1980, contudo, o levante homossexual pode ser percebido através do cinema, por exemplo, quando no início da década, os homossexuais passaram a ser apresentados com mais respeito no cinema brasileiro, em filmes como Pixote, a lei do mais fraco (1981), e O beijo da mulher Aranha (1985), de Hector Babenco; Vera (1987), de Sérgio Toledo, e A menina ao lado (1987), de Alberto Salvá, como nos mostra Luiz Nazário, em "Cinema Gay"18. Nazário explica que "se até o fim dos anos 80 a produção anual destes filmes nos EUA e na Europa era de apenas quatro ou cinco títulos, a partir dos anos 90 ela chega a 50 ou 60 títulos. De produção modesta, os filmes gay contam com um público fiel, cada vez mais assumido." ${ }^{19}$

17 MORICONI, Italo apud PINTO, Manuel da Costa. Sexualidades pós-modernas, CULT, São Paulo, ano VI, n. 66, p. 48, fev. 2003.

18 NAZÁRIO, Luiz. Cinema Gay, CULT, São Paulo ano VI n. 66, p. 60-61, fev. 2003.

19 Ibidem, p. 63. 
O momento é de uma luta pela inclusão, mas o livro inédito de Piva luta pela exclusão; ele clama por um espaço do passado, uma nostalgia pelo ideal de beleza Greco-romano, bem como pelas relações pederastas, mais afins a um Satyricon, em que não só homossexualismo, mas o sexo em geral, está em primeiro plano. Desse modo, o Corações de hot-dog se aproxima, nos termos de Moriconi, mais ao erotismo de manifestação atemporal e anacrônica do que ao movimento gay que tende a ser datado e determinado como momento histórico. Não se pode dizer que não haja, entretanto, a reivindicação ao direito de uma vida feliz e repleta de prazer para o homossexual, mas a reivindicação se estende ao heterossexual; ele também tem direito ao amor livre, às paixões diversas, à orgia, como pudemos ler no "Poema Elétrico do Cu".

Para Moriconi, existe na criação homoerótica,

um tipo de valoração específica, distinto do valor estético no sentido tradicional, se por esse se entende um certo nível de sublimação, de perfeição e beleza, de busca de uma modelização válida para as instituições pedagógicas. Existem textos ou objetos de arte que podem ter um valor positivo na questão homoerótica e negativo na estética stricto sensu, assim como pode se dar o contrário. Podemos citar o uso da imaginação pornográfica. Esse uso pode se concretizar de maneira negativa ou positiva em cada um dos aspectos. ${ }^{20}$

Não se trata de uma "literatura homossexual", o que seria uma tentativa generalizante de rotular a produção artística de escritores homossexuais como Genet, Proust, Whitman ou Garcia Lorca, cujas obras são completamente diferentes. Se entendermos a produção poética de Piva como literatura homoerótica, devemos considerá-la uma tentativa de ampliação do espaço homossexual até a dimensão em que as barreiras que o circundam se dissipem e este espaço de diferença seja incorporado à sociedade, não com indiferença, mas com um caráter destrutivo, não como simples aceitação, mas como forma de abrir brechas na realidade, uma forma de arte que faça pensar. $O$ "caráter destrutivo" da poesia homoerótica de Piva, parece se estender a um sentido último de felicidade, em que a destruição, que se "alinha na frente de combate dos tradicionalistas", como escreve Walter Benjamin, abre espaços para um suspiro profundo tendo à vista a efemeridade da vida, tendo à frente

\footnotetext{
${ }^{20}$ MORICONI, Italo apud PINTO, Manuel da Costa, Sexualidades pós-modernas, op cit., p. 50.
} 
uma felicidade voluptuosa e a jovem serenidade do espaço vazio. ${ }^{21}$

Georges Bataille escreve que o mérito de Malcolm de Chazal foi "haber 'visto' la voluptuosidad dentro de un movimiento, donde la esencia del movimiento es salida [...], ya que concierne a la sensación - que lo acelera y lo precipita - de la imposibilidad del reposo."22 Um movimento assim, incessante, destruidor, na ventania de um ciclone, não está disposto a determinações e não se presta a um sentido último, pois "o caráter destrutivo não tem o mínimo interesse em ser compreendido."23

${ }^{21}$ Cf. BENJAMIN, Walter. O Caráter Destrutivo. In: Documentos de cultura, documentos de barbárie: escritos escolhidos. Trad. Celeste H. M. Ribeiro de Sousa et al. São Paulo: Cultrix, 1986, p. 187-188.

22 BATAILLE, Georges. La felicidad, el erotismo y la literatura, op. cit., p. 99.

${ }^{23}$ BENJAMIN, Walter. O Caráter Destrutivo, op. cit., p. 187. 